\title{
Early Childhood Science and Engineering: Engaging Platforms for Fostering Domain-General Learning Skills
}

\author{
Andres S. Bustamante ${ }^{1, *}$, Daryl B. Greenfield ${ }^{2}$ and Irena Nayfeld ${ }^{3}$ \\ 1 School of Education, University of California, Irvine, 3200 Education Bldg, Irvine, CA 92697, USA \\ 2 Department of Psychology, University of Miami, 5665 Ponce de Leon Blvd, Coral Gables, FL 33143, USA; \\ dgreenfield@miami.edu \\ 3 Department of Early Childhood Education, East Tennessee State University, Johnson City, TN 37614, USA; \\ nayfeld@etsu.edu \\ * Correspondence: asbustam@uci.edu; Tel.: +1-949-824-7367
}

Received: 15 May 2018; Accepted: 7 September 2018; Published: 11 September 2018

\begin{abstract}
Early childhood science and engineering education offer a prime context to foster approaches-to-learning (ATL) and executive functioning (EF) by eliciting children's natural curiosity about the world, providing a unique opportunity to engage children in hands-on learning experiences that promote critical thinking, problem solving, collaboration, persistence, and other adaptive domain-general learning skills. Indeed, in any science experiment or engineering problem, children make observations, engage in collaborative conversations with teachers and peers, and think flexibly to come up with predictions or potential solutions to their problem. Inherent to science and engineering is the idea that one learns from initial failures within an iterative trial-and-error process where children practice risk-taking, persistence, tolerance for frustration, and sustaining focus. Unfortunately, science and engineering instruction is typically absent from early childhood classrooms, and particularly so in programs that serve children from low-income families. However, our early science and engineering intervention research shows teachers how to build science and engineering instruction into activities that are already happening in their classrooms, which boosts their confidence and removes some of the stigma around science and engineering. In this paper, we discuss the promise of research that uses early childhood science and engineering experiences as engaging, hands-on, interactive platforms to instill ATL and EF in young children living below the poverty line. We propose that early childhood science and engineering offer a central theme that captures children's attention and allows for integrated instruction across domain-general (ATL, $\mathrm{EF}$, and social-emotional) and domain-specific (e.g., language, literacy, mathematics, and science) content, allowing for contextualized experiences that make learning more meaningful and captivating for children.
\end{abstract}

Keywords: approaches to learning; executive functioning; early childhood; science; engineering

\section{Introduction}

In an effort to build the full complement of school readiness competencies among young children, domain-general skills such as approaches-to-learning and executive functioning are powerful levers for change [1,2]. Yet, while there is wide acknowledgement that the components of approaches-to-learning (e.g., persistence, motivation, open-mindedness, acceptance of novelty and risk, group learning, and sustained focus) and executive functioning (e.g., working memory, cognitive flexibility, and inhibition) are important for early success, these skills are under-represented in early childhood classrooms [3-5]. Even in cases where teachers are aware of approaches-to-learning and 
executive functioning - and their importance for learning and development-these skills are difficult to teach devoid of academic content. To help a child to exercise persistence or to sustain focus, or to practice being cognitively flexible, teachers need an engaging context that can capture children's attention and capitalize on their inherent drive to understand their world [6].

Early childhood science and engineering education offers a prime context to foster approaches-to-learning and executive functioning by eliciting children's natural curiosity, providing a unique opportunity to engage children in hands-on learning experiences that promote critical thinking, problem solving, collaboration, persistence, and other adaptive domain-general learning skills [7,8]. Indeed, while engaging in a science experience or designing an engineering solution to a problem, children make observations and predictions, engage in collaborative conversations with teachers and peers, and think flexibly in planning and carrying out investigations to answer their questions, and design engineering solutions to their problems. Inherent to science and engineering is the idea that one learns from initial failures within an iterative trial-and-error process where children practice risk-taking, persistence, tolerance for frustration, and sustaining focus. Early childhood science and engineering capture children's attention and stimulate organic opportunities for educators to scaffold children in exercising these critical domain-general learning skills. In this manuscript, we aim to accomplish three goals: (1) describe the state of early childhood science and engineering (mainly in the context of the United States); (2) offer theory and evidence suggesting that early science and engineering are ideal platforms to develop domain general learning skills; and (3) present a pathway towards supporting the early childhood education workforce in capitalizing on the many benefits of early science and engineering education.

\section{Early Childhood Science and Engineering}

Unfortunately, in the United States, science and engineering instruction is under represented in early childhood classrooms, and particularly so in programs that serve children from low-income families [9-11]. Additionally, teacher preparation programs typically do not prepare preschool teachers to teach Science Technology Engineering and Math (STEM) content [12-14]. Consequently, early childhood teachers often report feeling intimidated and under-prepared to teach science, and in some cases, they self-select into early childhood specifically to avoid it [15]. Part of this unpreparedness and avoidance of science in early childhood is a consequence of our nations' approach to science education. For most of us, science conjures memories of high school chemistry where we had to memorize elements on the periodic table, or of high school physics where we were taught to apply a complicated formula to obtain the "correct" answer to an obscure problem unrelated to our daily lives. Further, since engineering education has traditionally not been part of the general $\mathrm{K}-12$ education experience (i.e., the beginning of primary school (age 5) through the end of secondary school (age 18)), early childhood educators have minimal background in engineering pedagogy, and engineering education has been largely absent from purposeful coverage in early childhood. Brophy and colleagues reviewed several engineering curricula in the K-12 setting, and they highlight the urgent need for introducing engineering at younger ages, but they only refer to small pilots and case studies at the preschool level [16]. There has been a recent emphasis on bringing engineering to the $\mathrm{K}-12$ environment through curricula [17] and interactive websites that provide educators with resources that connect them to practicing engineers (e.g., www.teachengineering.org and www.linkengineering.org). For example, The Institute for P-12 Engineering Research and Learning (INSPIRE) at Purdue University has developed engineering academies for elementary school teachers, and has done recent work on extending engineering opportunities to women and under-represented minorities at the K-12 level [18]. However, at the early childhood level, engineering is more scarce-Bagiati and colleagues [19] conducted a review on early childhood engineering curricula and materials, and concluded that "pedagogically and content-reliable sources are limited in number and difficult to identify among the plethora of information." Even so, there has been recent work on early childhood engineering, Gold and colleagues demonstrated that large block play elicited more engineering behaviors in preschoolers than 
play in traditional playgrounds and play in the dramatic play area [20]. Further, Davis, Cunningham, \& Lachapelle [21] designed an engineering curriculum called "Wee Engineer" specifically for early childhood classrooms. Finally, Bagiati \& Evangelou [22] have developed a preschool STEM curriculum with a specific emphasis on engineering. Despite these recent efforts, more research and resources for early childhood engineering are essential for the development and progress of early STEM education. A review by Tolmie, Ghazali, and Morris [23] suggests three core components of early science learning: accurate observation, the ability to reason about causal connections, and the knowledge of mechanisms that explain those connections. Early engineering may provide a learning context that is uniquely conducive to building these core components, as engineering activities typically involve observing physical phenomena, and identifying and manipulating causal connections to build a tool or structure that solves a problem. By manipulating physical objects and observing how those manipulations change the behavior of the tool or structure, children receive real-time feedback, which contributes to their understanding of causal relationships. Further, the five-step engineering design process [21] is particularly conducive to the inquiry cycle and iterative hands-on science learning. The first step, "ask" requires children to identify the problem and explore how others have approached it. The next step, "imagine" has children brainstorming ideas and deciding on the best one. Then, children "plan", which can involve drawing a diagram or listing the required materials. Next, they "create" by following their plan and testing their idea. Finally, children "improve" by analyzing which aspects of their designs worked, and which could be improved, and modifying and retesting their approach. This systematic process of observation and manipulation is in line with calls from the field of education that emphasize the need to provide earlier exposure to STEM experiences, and to increase the focus on the process of scientific inquiry [24,25].

Accordingly, in a major revision to fact-based rote learning of large amounts of unrelated science content-described as "a mile-wide and an inch deep"- a new conceptual framework from the Next Generation Science Standards (NGSS) for K-12 science education is being implemented [26]. This new framework puts forth a three-dimensional approach to science education, emphasizing learning science by doing science. It proposes eight scientific practices (asking questions and defining problems, developing and using models, planning and carrying out investigations, analyzing and interpreting data, using mathematics and computational thinking, constructing explanations and designing solutions, engaging in argument from evidence; obtaining, evaluating and communicating information), to acquire science content in four science disciplinary areas (life science, physical science, earth and space science, technology and engineering) that are relevant for students' everyday lives. In addition, there is a major focus on attending to crosscutting concepts (i.e., patterns, cause-and-effect relationships, scale, proportion, and quantity, systems and system models, energy and matter, structure and function, stability and change) that have relevance not only across all science content, but also in most areas of our lives (e.g., cause-and-effect is ubiquitous in our lives-actions have consequences no matter what the context).

In this paper, we describe the high relevance and application of this framework to learning and development, beginning at birth and continuing through all of early childhood. The "Early Science Framework" [27], which we have adapted from the new NGSS K-12 framework [26], takes advantage of young children's natural curiosity and goal-directed motivation to understand the world in which they live. The focus of learning science by doing science also advantages the hands-on interactive activities that are emblematic of high-quality early-childhood learning. Our intended goal is to create continuity in young children's learning from birth through to high school that is meaningful, engaging, and goal-directed. In describing our approach to creating this strong foundation for learning, we also highlight science and engineering as ideal contexts to foster domain-general learning skills.

Early childhood science and engineering can elicit high-quality teacher child interactions. Fucillo and Greenfield [28], conducted classroom observations-using the Classroom Assessment Scoring System (CLASS; [29])—across four activity types: circle time, math, story book, and science. Teachers were rated no differently across activity types in the domains of emotional support 
(teacher warmth and sensitivity), and classroom organization (preparedness for the lesson, pacing, and managing behavior). However, in the domain of instructional support (developing concepts, providing high-quality feedback, and using rich language) teachers were rated significantly higher during science activities.

Science and engineering can also offer opportunities for children to learn across school-readiness domains. For example, during science and engineering experiences, children are often recognizing patterns, engaging in measurement, comparing and contrasting, and sorting and organizing, all of which are critical skills in early childhood mathematics [30]. Children also learn new vocabulary in the way we know children learn best, when new words are relevant and meaningful to them because they arise in the context of an engaging learning experience where they are invested in solving a problem or answering a question [31]. Children may also be more excited and attentive during book readings if the book is about a topic with which they just had an exciting, hands-on experience. Science and engineering often take place in a group setting where children have to share and cooperate, promoting social emotional development. Further, small-group science activities like sink-and-float lessons have been demonstrated to promote collaborative learning and enhance young children's cognitive development [32,33]. Science education is posited to be an ideal context to foster creativity and imagination [34]. Finally, science and engineering are ideal for fostering approaches-to-learning and executive functioning $[7,8,35]$.

\section{Early Science and Engineering Are a Natural Fit with Domain General Skills}

Approaches-to-learning is recognized by Head Start as one of the five core school readiness domains, and approaches-to-learning in preschool is predictive of academic success into late elementary school $[1,36]$. Executive functioning is widely studied and recognized for its predictive power for later cognitive ability and academic success [37-39]. Entire early childhood curricula have been developed to target executive functioning (Tools of the Mind; [40]) and approaches-to-learning (EPIC; [41]), demonstrating the need to acknowledge the importance of these domain-general learning skills and to ramp up efforts to promote an intentional focus on fostering them in early childhood. Two recent studies from the United Kingdom highlighted the dearth of science education in early childhood classrooms, and emphasized that the ideal manifestation of science education is as a process of inquiry that fosters domain-general learning skills [42,43].

Emerging evidence from the United States suggests a unique relationship between early childhood science and engineering, and the domain-general learning skills of approaches-to-learning and executive functioning. Nayfeld, Fucillo, \& Greenfield [7] examined the predictive power of executive functioning skills in 300 racially and ethnically diverse preschoolers served by Head Start. They found that while executive functioning predicted gains in academic school readiness across the preschool year in early literacy, vocabulary, math, and science, executive functioning predicted gains in science more strongly than the other readiness domains. Bustamante, White, \& Greenfield [8] demonstrated a very similar pattern of results using approaches-to-learning as the predictor in a highly similar population of children. Approaches-to-learning predicted gains across the Head Start school year in the domain of early science, more so than in math and early literacy skills. These two studies demonstrate a unique connection between early childhood science and the domain-general skills of executive functioning and approaches to learning, where they predict science learning more strongly than other school readiness domains (i.e., literacy, vocabulary, and math). Most recently, Bustamante, White, \& Greenfield [35] evidenced a bi-directional relationship between early science and approaches-to-learning, where gains in science readiness across the school year predicted gains in approaches-to-learning, and vice versa. This suggests a symbiotic relationship where science is helping children to foster approaches-to-learning skills, and approaches-to-learning are helping children to learn more science.

To illustrate this relationship, let us take an example where a class decides to recreate the story of the three little pigs after reading the book as a class. Children could break into four groups, 
where one group is the wolf and the three other groups are each one of the pigs. Working in these teams allows children to exercise communication and collaboration, which are both approaches to learning skills and one of the scientific practices. Their first step would be to make a plan (a key element of both approaches to learning and executive functioning) and carry out an investigation (planning and carrying out an investigation is one of the eight science/engineering practices in the new K-12 framework, and in the Early Science Framework). Each of the three pig groups would then decide what kind of materials they want to use to build their houses (a key step in the engineering and design process). They would have to demonstrate cognitive flexibility and working memory (two components of executive functioning) to decide which materials from the classroom to use to build their house, and not repeat the materials of the two other pig groups (the properties of objects is a key physical science content area in both the K-12 framework and the Early Science Framework). They would sustain focus to build their houses, and remain motivated when their original designs were not as solid and stable as they anticipated (sustained focus and motivation are two approaches to learning skills, and iterative design is fundamental to the engineering process). Finally, children would have to take the risk of putting their house up to the test of the big bad wolf without knowing the outcome, and the acceptance of novelty and risk is an element of approaches to learning (again, one of the $\mathrm{K}-12$ and early science framework practices, while testing designs is also essential in engineering). The wolf group would have their own planning to do. They would decide how they will test the houses (e.g., their breath, a fan, a blow-dryer) and would need to inhibit their urge to use their hands if any of the houses withstood their blowing (cognitive inhibition is a key executive functioning skill). Meanwhile, during this whole experience, children are provided the opportunity to learn important science and engineering concepts like force and stability, and the properties of objects, and engage in science and engineering practices like predicting, observing, testing and revising hypotheses, drawing conclusions from evidence, and attend to crosscutting concepts including cause-and-effect, structure-function, system and system models, and stability and change.

This example highlights the potential for science and engineering activities to serve as a context to foster domain-general learning skills (i.e., approaches to learning and executive functioning), and for those same domain-general learning skills to help children succeed in science and engineering experiences. In order to capitalize on this unique symbiotic relationship, we must support teachers in providing more science and engineering opportunities in their classrooms, and help them to be deliberate about targeting approaches-to-learning and executive functioning.

\section{The Early Science Initiative}

The Early Science Initiative (ESI) is a science and engineering intervention for children aged $0-5$ years of age, which is currently being implemented in four early childhood centers in the Educare Learning Network [27,44]. ESI takes a multi-pronged professional development training approach that includes in-person, video-conference, and web-mediated training. Although there is some direct training with teachers, the project also relies heavily on a "train the trainer" approach, where ongoing professional development is provided for mentor teachers, who in turn work with the teachers in their center. The approach is to show teachers how to build science and engineering instruction into activities that are already happening in their classrooms, which boosts their confidence and removes some of the stigma around science and engineering. In this project, science and engineering have quickly become favorite content areas for many teachers as they begin to notice the children's excitement and engagement in the science and engineering experiences that are already happening in their classrooms.

In early childhood, science and engineering are naturally occurring, engaging, and goal-directed hands-on, minds-on, interactive activities where children plan and carry out investigations or solve problems instead of memorizing facts. Children, however, can only go so far on their own, making the role of the adult critical for children's effective science and engineering learning [21]. During initial visits to ESI classrooms, teachers apologized for not doing more science and engineering. They felt 
unprepared for teaching science and engineering, and felt the pressure of spending more time on language, literacy, and math activities. The goal of ESI is to make teachers aware that there are already science and engineering experiences happening in their classroom, and providing them with the knowledge and the transfer of knowledge to practice, and the opportunity to reflect on their practice. The project also draws attention to the opportunities for including multiple areas of school readiness (e.g., math, language, approaches to learning, and executive functioning) into these engaging, goal-directed science experiences [27]. Next, we provide two examples to illustrate this approach.

The first example focuses on young children's fascination with water and their constant opportunity to interact with this material. Objects that float versus sink in water is a typical science activity in many early-childhood classrooms. One approach that the adult might take to a sink-and-float activity is an entirely child-directed small group activity by providing the children with lots of different objects and letting them freely explore sinking and floating. Young children thoroughly enjoy such an activity, but when they do this on their own, without any adult scaffolding, it is not clear what they have learned, beyond possibly rote remembering which specific object sank and which floated. Suppose on the other hand that the adult facilitates a small group activity in which each child is asked to use a balance scale with a predetermined weight in one bucket, and measure out enough modeling clay to make the scale balance. A discussion about each child having the same amount of modeling clay could be tested using the balance scale (using math and computational skills). The teacher then asks the children to brainstorm about molding their modeling clay into a shape that would sink (designing and using models), make predictions from their brainstorming, and talk about what prior information informed their predictions. Once a consensus shape has been agreed upon by the children, with appropriate scaffolding by the teacher, each child makes that shape, and in turn drops their shape (a ball is a likely choice) into the water (planning and carrying out investigations). The results (making observations) that all the ball-like modeling clay shapes sink, are documented (e.g., photographed, written by the teacher, drawn by the children; analyzing and interpreting data). The teacher could then ask the children to think about molding their modeling clay into a shape that would float, following the same format, and engaging the children in the same scientific practices, and in an engineering design process (making observations, asking questions, making predictions, planning and carrying out investigations, prototyping, and testing different designs). With appropriate scaffolding from the teacher (e.g., prompting the children to think about objects they have seen float on water, and what they noticed about the shape of such objects), children will mold their modeling clay into a "boat-like" structure, and test to see if their boat floats (planning and carrying out investigations). If any such "boats" sink, further discussion and testing would address (constructing explanations) why a particular boat sank (e.g., it had a hole in the bottom or the sides were not made high enough to keep the water out). A reflection with the children on what was learned builds the children's foundational domain content knowledge in physical science, the role of shape in influencing whether an object made of exactly the same material might sink or float (the properties and attributes of a material), and surfacing and making visible the crosscutting concept of structure and function, while engaging in a series of scientific practices, and the engineering design process, as a means to solving problems and answering questions in a hands-on engaging experience.

After a series of hands-on workshops and continuous job-embedded professional development via reflective coaching sessions, many teachers in the ESI intervention reported feeling more comfortable and confident in identifying and supporting naturally occurring science and engineering experiences and investigations that draw upon children's goal-directed interests. The next step is to support teachers in intentionally targeting approaches to learning and executive functioning skills in the context of these science and engineering experiences. The following example illustrates how this can be done. Let's say that a class has an upcoming field trip to the zoo. The teacher notices several children playing with animal toys during center time. Seizing the opportunity to generate excitement for their upcoming trip and make a meaningful connection between science and engineering learning objectives and children's lives, the teacher brings the children together and asks if they want to make 
a zoo. Group activities are easy to implement for teachers, and they provide an excellent way to foster approaches to learning and executive functioning skills. First, the children gather all of the toy animals in the classroom and start building the structures to house the animals with blocks in the block area (engaging in the engineering process). They might initially build a single enclosure. The teacher could prompt them to think about which animals could be together, which ones need to be separated and why (engaging the approaches to learning the skill of strategic planning). With teacher scaffolding, they could observe the different features of the animals (e.g., do they have sharp teeth or flat teeth?) and discuss how the physical characteristics of an animal affect its behavior (e.g., animals with sharp teeth eat meat, and animals with flat teeth eat plants). While the children are sorting the animals, a child may put a zebra and a lion in the same group. The teacher can prompt that child to think back to the strategic plan (separate carnivores from herbivores), causing the child to exercise their working memory (a key component of executive functioning) and correct the error. Once the animals were sorted into groups, children would build the exhibits. A teacher could ask the children if different animals would need different kinds of exhibits (a basic engineering design question). Do the walls of the lion or tiger exhibits need to be taller than the walls for a peacock or a turtle? Do they need to be stronger and harder to knock down? Why? Teachers can encourage children to be cognitively flexible and open-minded (core skills of executive functioning and approaches to learning respectively) as they construct the enclosures, by asking guiding questions that help the children make revisions to improve their designs (e.g., laying the blocks vertically instead of horizontally to maximize height with fewer blocks). The teacher may notice that one of the younger children in the group is attentive but not contributing ideas. The teacher could gain the group's attention and ask that child's opinion on where a certain exhibit should be placed and why (providing an opportunity for the child to exercise their approaches to learning skill of vocal engagement). This zoo activity gives teachers and children a chance to engage in critical thinking and hands-on engineering in an engaging and playful context. At the same time, children are learning core science and engineering content (e.g., animal habitats and diet, and how to build stable structures), crosscutting concepts (e.g., structure and function relationships such as the features of an animal or building change its function), and they are engaging in science and engineering practices (e.g., observing, sorting, categorizing, and drawing conclusions based on evidence). This pre-trip experience would result in a more intentional and focused visit to the zoo. Children with adult support would generate a series of questions that they could investigate at the zoo (e.g., how do enclosures vary; how do the actual zoo structures compare to the model they built). The teacher would also support the children in preparing for their investigations (e.g., bringing binoculars, devices for taking pictures and videos, materials to document what they saw including pictures of animals). Once back from the trip, further engagement in science and engineering practices, executive function, and approaches to learning skills would occur as they document what they saw and learned, reflect on what was different from their predictions, and analyze the pictures and videos they took to redesign their model zoo. The above example illustrates how teachers can employ subtle strategies that may make meaningful differences in children's approaches to learning, and the development of executive functioning skills over time-facilitating group activities, asking children to plan, asking children to think back on their plans and decisions, prompting children to engage verbally and talk through ideas, and encouraging children to be flexible and open-minded-provide opportunities for children to bolster important domain-general skills. The ESI teachers will work to identify and capitalize on the many opportunities to build approaches to learning and executive functioning skills during science and engineering experiences.

\section{Empowering Teachers to Be Science Thinkers and Learners}

The ESI project endeavors to empower teachers to become experts in science and engineering pedagogy, and fully capable of developing activities based on the interests that are demonstrated by the children in their classrooms. While this is a challenging goal, the necessary supports are provided to allow teachers to think flexibly and to extend science and engineering opportunities that arise 
organically in the classroom. The primary support is the Early Science Framework, which details the key science and engineering practices, disciplinary core ideas, and crosscutting concepts that children should learn in early childhood. This framework provides teachers with a set of defined practices and important concepts that can be applied across multiple settings and topics to engage children in answering their goal-directed questions about the world in which they live. The framework is particularly useful for educators who lack confidence in their knowledge of science and engineering content and pedagogy, helping them to see and support the science and engineering that is already happening in their classroom. The second resource is an instructional coach who can help develop and provide feedback on science and engineering lesson plans, as well as engage in reflective conversations on teachers' experiences implementing science and engineering activities. These reflective coaches are aided by an interactive web-based platform that extends their reach and mitigates some of the burden of scheduling and engaging in face-to-face meetings-enhancing the generalizability of the ESI model [45].

Another intervention by Brenneman, Lange, and Nayfeld [46] sought to impact early childhood educators' attitudes and beliefs, knowledge, and teaching practices in STEM via a research-based professional development model. This effort is unique in that the design of the model itself is based on concrete best practices in what we know about early childhood STEM learning, as well as best practices in adult learning to fully support and build capacity for the participating educators. Specifically, they outline 10 key levers that were intentionally built into the model as it was developed. These are: (1) includes educators and administrators in the ongoing design; (2) includes training for coaches; (3) builds teachers' content knowledge; (4) attends to teachers' attitudes and beliefs; (5) engages with teachers at multiple levels (large group, small group, and one-on-one); (6) is connected to classroom practice; (7) involves educators reflecting on practice, with feedback; (8) creates a community of practice; (9) is sustained and long term; (10) is individualized. This approach acknowledges that preschool teachers and district coaches often do not have prior training in teaching science, engineering, technology, and math, and they are therefore provided a framework for workshops, coaching, and learning communities around developmentally appropriate STEM concepts while using an iterative design framework that seeks feedback and the construction of resources based on what teachers and coaches identified as being lacking or most helpful.

During the workshops, teachers are given the background for a science or math concept-this, however, was not enough. Participating teachers requested concrete examples, and hands-on activities that they could readily use in their classrooms. In response, the professional development evolved to provide hands-on small group learning experiences that built children's understanding and experience with this concept, through interactive, inquiry-driven explorations. Teachers were given model lesson plans that described a progression of activities over the course of several days (or longer)-these plans included the needed materials, the relevant literature to tie the lessons to literacy objectives, a list of key words in Spanish (the dominant language of most children in the participating classrooms), and a breakdown of what a scaffolded series of activities could look like.

Once the concept is presented and the discussion of developmental trajectories, pedagogical content knowledge, and teaching strategies takes place in a large group, teachers rotate in small groups to discuss and practice three different small group activities during the second half of the workshop. They also receive a small bag of materials for one of the activities, to make the implementation easy. All lessons are designed to be implemented in classrooms in under-resourced settings, and without placing a financial burden on the teachers-therefore, while some suggested materials may have to be purchased, great care is taken to create activities that use materials that are already present in most US pre-K classrooms, or ones that can be easily and cheaply acquired at home or from a "99 cent" store by the teacher, coach, or principal. Suggestions and alternatives are given to make the activity possible and realistic for the educator.

One of the modules covered focuses on the concept of Change and Transformation. Within this module, teachers are given an overview of the crosscutting concept of change and transformation, 
its relevance across earth science (e.g., changing weather), life science (e.g., life cycles), and physical science (e.g., changes in matter), and how these can be explored in a preschool classroom. Then, teachers discuss the opportunities to observe how change takes place, inquire and think critically about the process, predict how we can affect change, design experiments, and restructure beliefs based on new conclusions. After a whole group discussion, teachers engage in hands-on small-group activities that give specific examples for making this topic actionable, with progressions of activities that build on each other and are flexible so that teachers can make them work for their students and existing curricula.

One example activity focuses on change and transformation in the context of food; specifically, how oranges become orange juice. First, the teachers are asked to think about how we transform food-oranges becoming orange juice, apples turning into applesauce, or tomatoes becoming ketchup. Teachers are supported through a discussion of how one might engage children in thinking about and discussing these concepts. A child's first reaction to the question "Where does orange juice come from?" might be "From the supermarket!" To dig deeper, teachers are asked to think of open-ended questions they might ask to scaffold children's reasoning as they go through the process of connecting an orange to the orange juice that they buy in the store. Notably, the teachers are given strategies to make the learning visual, such as to bring in real oranges, tools, and materials, and to use body language and signage to connect the concepts for children at all levels, including dual language learners. In contrast to a lesson where students are directly told that orange juice is made with oranges, or are given a concrete set of steps to follow to make orange juice, a small group activity is proposed in which the children are asked to think about how they might make orange juice out of an orange. What do we need to do with the orange? As children make suggestions ("Cut it!", "Smash it!"), they are encouraged to try them. These exercises encourage persistence and cognitive flexibility as the children have fun experimenting and observing the results of their method, and that of their peers. Over the course of several small group activities, teachers can introduce different tools that might make getting the juice out more efficient, allowing children to create experiments: for example, they might want to compare squeezing an unpeeled orange, squeezing a peeled orange, and using a juicer. Teachers are given ideas of how to lead such an experiment, collect data, and follow students' natural inquiry to encourage creative thought, collaboration, and sustained engagement. This seemingly simple activity can fill several days or even weeks, spilling over into different parts of the day and academic domains, leading to rich discussion, and potential continuation with other food transformations, and more complex experiments that grow out of the children's increasing understanding and curiosity.

Two other components are key in supporting the teachers. As in the ESI project, reflective coaching was built into the supports so that the district coaches and teachers are able to review the science activities together, discuss successes and areas for further improvement, and create a cycle of increasingly effective STEM practice. A third aspect, professional learning communities (PLCs), bring teachers together to discuss the ways in which they implemented the STEM activity in their classroom (they are encouraged to use the activity as a starting point, and shape it to work for their curricula, their setting, and their children), talk about challenges they encountered, and brainstorm together with their colleagues. This model for collaborative professional development and learning, shown to positively affect student achievement [47], is applied in this model to supporting STEM in early childhood settings. The teachers reported that these three aspects of the model improved their STEM practice [46]. A randomized control trial testing the intervention reported significant growth in teachers' and coaches' attitudes and beliefs around teaching STEM, as well as STEM knowledge [48,49].

An additional support that is currently in development is early science learning trajectories. Learning trajectories provide teachers with an evidence-based approach to introducing content to their classrooms by detailing sequential levels of knowledge that children typically progress through in a specific domain. This allows teachers to identify the students' current levels of understanding, and plan intentional experiences to scaffold their progress to the next learning goal on the trajectory [50]. Early childhood math has well-specified learning trajectories that have been at the center of highly 
successful intervention efforts [51]. However, this resource does not exist in early science. Therefore, learning trajectories across all of the practices, core ideas, and crosscutting concepts in the Early Science Framework would be a powerful resource for early educators. To our knowledge, only one other research group has begun to conduct the conceptual research required to construct an early science learning trajectory [52]. We encourage other early childhood researchers to join this effort, as comprehensive trajectories could have a profound impact on the field of early childhood science and engineering education.

\section{Implications for Early Childhood Education}

Moving forward, we propose that early childhood science and engineering be used as a central theme that captures children's attention, and allows for integrated instruction across domain-general (approaches-to-learning, executive functioning, and social-emotional development) and domain-specific (e.g., language, literacy, mathematics, science, and engineering) content, providing contextualized experiences that make learning more meaningful and captivating for children.

There has been a recent emphasis in the field on integrated comprehensive curricula. For example, Sarama and colleagues [53], developed an interdisciplinary preschool curriculum called "Connect4Learning" that targets science, literacy, math, and social-emotional development in a project-based approach. These comprehensive approaches allow teachers and children alike to draw meaningful connections between different content areas, making for rich learning experiences [54]. We see great promise in this curricular approach, and we hold that science and engineering themes offer an excellent context to foster approaches-to-learning and executive functioning, in addition to literacy, math, and social emotional skills. Providing key supports, such as the Early Science Framework, continuous job-embedded professional development (e.g., coaching), and evidence-based learning trajectories, may boost the confidence of teachers in engaging in science and engineering pedagogy, and can empower them to become science thinkers and lifelong learners who capable of identifying and extending organic science and engineering learning experiences that arise from the interest of the children in their classroom. Further, STEM professional development efforts should strive to meet the 10 key levers put forth by Brenneman, Lang, and Nayfeld [46], in the professional development model that is discussed above.

\section{Conclusions}

This article offers a theoretical argument for early childhood science and engineering as ideal contexts to foster domain-general learning skills (e.g., approaches to learning and executive functioning) that can help children to achieve school and life success. We reviewed recent research that suggests a unique relationship between early science and domain-general skills, and provided a series of examples that demonstrate how teachers can capitalize on children's goal-directed interests to elicit science and engineering learning, and provide opportunities for children to exercise their approaches to learning and executive functioning skills. This article also highlights the great need for improvement of the infrastructure of science and engineering education in the United States, and offers that the new $\mathrm{K}-12$ science framework is a valuable resource toward that end. In order to maximize the effect of the new framework, continuity between early childhood and later grades is essential, and the new Early Science Framework, adequate professional supports (including the 10 key levers of STEM professional development), and early science learning trajectories provide a clear path towards that goal. We believe that an expanded focus on high-quality early-childhood science and engineering education, and intentional instruction of domain-general learning skills could have great implications for educational outcomes-particularly for young children from low-income families.

Author Contributions: All three authors contributed to all facets of this paper.

Funding: This article was supported by funding from the Institute of Education Sciences training grant (R305B150014). 
Conflicts of Interest: The authors declare no conflict of interest.

\section{References}

1. Li-Grining, C.P.; Votruba-Drzal, E.; Maldonado-Carreño, C.; Haas, K. Children's early approaches to learning and academic trajectories through fifth grade. Dev. Psychol. 2010, 46, 1062-1077. [CrossRef] [PubMed]

2. Ursache, A.; Blair, C.; Raver, C.C. The Promotion of Self-Regulation as a Means of Enhancing School Readiness and Early Achievement in Children at Risk for School Failure. Child Dev. Perspect. 2012, 6, 122-128. [CrossRef]

3. Vitiello, V.E.; Greenfield, D.B.; Munis, P.; George, J. Cognitive Flexibility, Approaches to Learning, and Academic School Readiness in Head Start Preschool Children. Early Educ. Dev. 2011, 22, 388-410. [CrossRef]

4. McDermott, P.A.; Rikoon, S.H.; Fantuzzo, J.W. Tracing Children's Approaches to Learning through Head Start, Kindergarten, and First Grade: Different Pathways to Different Outcomes. J. Educ. Psychol. 2014, 106, 200-213. [CrossRef]

5. Vitiello, V.E.; Greenfield, D.B. Executive functions and approaches to learning in predicting school readiness. J. Appl. Dev. Psychol. 2017, 53, 1-9. [CrossRef]

6. Greenfield, D.B. The power of inquiry: Why science belongs in early childhood classrooms (Chapter 7). In The Death of Rote Memorization: Early Grade Math and Science Learning in Latin America and the Caribbean; Näslund-Hadley, E., Bando, R., Eds.; Inter-American Development Bank: Washington, DC, USA, in press.

7. Nayfeld, I.; Fuccillo, J.; Greenfield, D.B. Executive functions in early learning: Extending the relationship between executive functions and school readiness to science. Learn. Individ. Differ. 2013, 26, 81-88. [CrossRef]

8. Bustamante, A.S.; White, L.J.; Greenfield, D.B. Approaches to learning and school readiness in Head Start: Applications to preschool science. Learn. Individ. Differ. 2017, 56, 112-118. [CrossRef]

9. Brenneman, K.; Stevenson-Boyd, J.; Frede, E.C. Math and science in preschool: Policies and practice. Presch. Policy Brief 2009, 19, 1-12.

10. Ginsburg, H.P.; Lee, J.S.; Boyd, J.S. Mathematics Education for Young Children: What It Is and How to Promote It; Social Policy Report; Society for Research in Child Development: Washington, DC, USA, 2008.

11. Morgan, P.L.; Farkas, G.; Hillemeier, M.M.; Maczuga, S. Science Achievement Gaps Begin Very Early, Persist, and Are Largely Explained by Modifiable Factors. Educ. Res. 2016, 45, 18-35. [CrossRef]

12. Anthony, G.; Walshaw, M. Effective Pedagogy in Mathematics/Pangarau: Best Evidence Synthesis Iteration (BES); Ministry of Education: Singapore, 2007.

13. Buysse, V.; Castro, D.C.; West, T.; Skinner, M. Addressing the needs of Latino children: A national survey of state administrators of early childhood programs. Early Child. Res. Q. 2005, 20, 146-163. [CrossRef]

14. Perry, B.; Dockett, S.; Harley, E. Preschool Educators Sustained Professional Development in Young Children's Mathematics Learning. Math. Teach. Educ. Dev. 2007, 8, 117-134.

15. Greenfield, D.B.; Jirout, J.; Dominguez, X.; Greenberg, A.; Maier, M.; Fuccillo, J. Science in the preschool classroom: A programmatic research agenda to improve science readiness. Early Educ. Dev. 2009, 20, 238-264. [CrossRef]

16. Brophy, S.; Klein, S.; Portsmore, M.; Rogers, C. Advancing engineering education in P-12 classrooms. J. Eng. Educ. 2008, 97, 369-387. [CrossRef]

17. Cunningham, C.M.; Kelly, G.J. Framing engineering practices in elementary school classrooms. Int. J. Eng. Educ. 2017, 33, 295-307.

18. Duncan, D.; Diefes-dux, H.; Gentry, M. Professional development through engineering academies: An examination of elementary teachers recognition and understanding of engineering. J. Eng. Educ. 2011, 100, 520-539. [CrossRef]

19. Bagiati, A.; Yoon, S.Y.; Evangelou, D.; Ngambeki, I. Engineering Curricula in Early Education: Describing the Landscape of Open Resources. Early Child. Res. Pract. 2011, 12, 2-15.

20. Gold, Z.S.; Elicker, J.; Choi, J.Y.; Anderson, T.; Brophy, S.P. Preschoolers' engineering play behaviors: Differences in gender and play context. Child. Youth Environ. 2015, 25, 1-21. [CrossRef]

21. Davis, M.E.; Cunningham, C.M.; Lachapelle, C.P. They Can't Spell “Engineering” but They Can Do It: Designing an Engineering Curriculum for the Preschool Classroom. ZERO TO THREE 2017, 37, 4-11.

22. Bagiati, A.; Evangelou, D. Engineering curriculum in the preschool classroom: The teacher's experience. Eur. Early Child. Educ. Res. J. 2015, 23, 112-128. [CrossRef] 
23. Tolmie, A.K.; Ghazali, Z.; Morris, S. Children's science learning: A core skills approach. Br. J. Educ. Psychol. 2016, 86, 481-497. [CrossRef] [PubMed]

24. DeJarnette, N. America's children: Providing early exposure to STEM (science, technology, engineering and math) initiatives. Education 2012, 133, 77-84.

25. Spaepen, E.; Bowman, B.; Day, C.B.; Chen, J.; Cunningham, C.; Donohue, C.; Worth, K. Early STEM Matters: Providing High-quality STEM Experiences for all Young Learners. Retrieved from Early Childhood STEM Working Group. 2017. Available online: http:/ / ecstem.uchicago.edu (accessed on 25 May 2018).

26. National Research Council. A Framework for K-12 Science Education, A Framework for K-12 Science Education: Practices, Croscutting Concepts, and Core Ideas; National Academies Press: Washington, DC, USA, 2012. [CrossRef]

27. Greenfield, D.B.; Alexandra, A.; Frechette, L. Unleashing the Power of Science in Early Childhood: A Foundation for High-Quality Interactions and Learning. ZERO TO THREE 2017, 37, 13-21.

28. Fuccillo, J.M. Higher-Level Instructional Interaction in Head Start Classrooms: Variation Across Teacher-Directed Activities and Associations with School Readiness Outcomes. Ph.D. Theses, University of Miami, Coral Gables, FL, USA, 2011.

29. Pianta, R.C.; La Paro, K.M.; Hamre, B.K. Classroom Assessment Scoring System (CLASS) Manual; Paul H. Brookes Publishing Company: Baltimore, MD, USA, 2008.

30. Clements, D.H.; Sarama, J. Learning Trajectories in Mathematics Education Learning Trajectories in Mathematics Education. Math. Think. Learn. 2009, 6, 81-89. [CrossRef]

31. Howe, C.; Tolmie, A.; Rodgers, C. Physics in the primary school: Peer interaction and the understanding of floating and sinking. Eur. J. Psychol. Educ. 1990, 5, 459. [CrossRef]

32. Howe, C. Collaborative group work in middle childhood. Hum. Dev. 2009, 52, 215-239. [CrossRef]

33. Harris, J.; Golinkoff, R.M.; Hirsh-pasek, K. Lessons from the Crib for the Classroom: How Children Really Learn Vocabulary. Handbook of Early Literacy Research. 2016; p. 490. Available online: http:/ /books.google. es/books?id=Lyxgk3cF6B4C (accessed on 4 April 2018).

34. Hadzigeorgiou, Y. Imaginative Science Education: The Central Role of Imagination in Science Education; Springer: Cham, Switzerland, 2016.

35. Bustamante, A.S.; White, L.J.; Greenfield, D.B. Approaches to learning and science education in Head Start: Examining bidirectionality. Early Child. Res. Q. 2018, 44, 34-42. [CrossRef]

36. McWayne, C.M.; Fantuzzo, J.W.; McDermott, P.A. Preschool Competency in Context: An Investigation of the Unique Contribution of Child Competencies to Early Academic Success. Dev. Psychol. 2004, 40, 633-645. [CrossRef] [PubMed]

37. Diamond, A.; Lee, K. Interventions shown to Aid Executive Function Development in Children 4-12 Years Old. Science 2011, 333, 959-964. [CrossRef] [PubMed]

38. Welsh, J.; Nix, R.L.; Blair, C.; Bierman, K.L.; Nelson, K.E. The Development of Cognitive Skills and Gains in Academic School Readiness for Children from Low-Income Families. J. Educ. Psychol. 2011, 102, 43-53. [CrossRef] [PubMed]

39. McClelland, M.M.; Cameron, C.E. Self-Regulation Early Childhood: Improving Conceptual Clarity and Developing Ecologically Valid Measures. Child Dev. Perspect. 2012, 6, 136-142. [CrossRef]

40. Bodrova, E.; Leong, D.J. Tools of the mind: Vygotskian approach to early childhood education. In Approaches Early Childhood Education; Rooparine, J.L., Jones, J., Eds.; Merrill/Prentice Hall: Bel Air, CA, USA, 2012; pp. 241-260.

41. Fantuzzo, J.W.; Gadsden, V.L.; McDermott, P.A. An Integrated Curriculum to Improve Mathematics, Language, and Literacy for Head Start Children. Am. Educ. Res. J. 2011, 48, 763-793. [CrossRef]

42. Marian, H.; Jackson, C. Inquiry-based learning: A framework for assessing science in the early years. Early Child Dev. Care 2017, 187, 221-232. [CrossRef]

43. McNerney, K.; Hall, N. Developing a framework of scientific enquiry in early childhood: An action research project to support staff development and improve science teaching. Early Child Dev. Care 2017, 187, $206-220$. [CrossRef]

44. Greenfield, D.B. The Early Science Initiative. Available online: http://project1.earlyscienceinitiative.org/ (accessed on 11 September 2018).

45. Connor, C.M. Commentary on the Special Issue on Instructional Coaching Models: Common Elements of Effective Coaching Models. Theory Pract. 2017, 56, 78-83. [CrossRef] 
46. Brenneman, K.; Lange, A.; Nayfeld, I. Integrating STEM into Preschool Education; Designing a Professional Development Model in Diverse Settings. Early Child. Educ. J. 2018, 1-14. [CrossRef]

47. Vescio, V.; Ross, D.; Adams, A. A review of research on the impact of professional learning communities on teaching practice and student learning. Teach. Teach. Educ. 2008, 24, 80-91. [CrossRef]

48. Mano, H.; Lange, A.; Nayfeld, I. Preliminary Effects of a Preschool STEM Professional Development Model on Teachers' Attitudes and Beliefs. In Proceedings of the American Education Research Association Conference, New York, NY, USA, 13-17 April 2018.

49. Nayfeld, I.; Lange, A.; Mano, H. Effects of a preschool professional development model on teachers' science and math knowledge. In Proceedings of the National Research Conference on Early Childhood, Arlington, VA, USA, 25-27 June 2018.

50. Clements, D.H.; Wilson, D.C.; Sarama, J. Young children's composition of geometric figures: A learning trajectory. Math. Think. Learn. 2004, 6, 163-184. [CrossRef]

51. Clements, D.H.; Sarama, J. Learning and Teaching Early Math: The Learning Trajectories Approach; Routledge: Abington, UK, 2014.

52. Allen, M.; Kambouri-Danos, M. Substantive conceptual development in preschool science: Contemporary issues and future directions. Early Child Dev. Care 2017, 187, 181-191. [CrossRef]

53. Sarama, J.; Brenneman, K.; Clements, D.H.; Duke, N.K.; Hemmeter, M.L. Interdisciplinary teaching across multiple domains: The C4L (Connect4Learning) curriculum. Implement. Stand.-Based Curric. Early Child. Classr. 2017, 1-52. [CrossRef]

54. Clements, D.H.; Hemmeter, M.L. Interdisciplinary Teaching Across Multiple Domains: The C4L (Connect 4 Learning); Routledge: New York, NY, USA, 2017.

(C) 2018 by the authors. Licensee MDPI, Basel, Switzerland. This article is an open access article distributed under the terms and conditions of the Creative Commons Attribution (CC BY) license (http:/ / creativecommons.org/licenses/by/4.0/). 